\title{
The ORF2 glycoprotein of hepatitis E virus inhibits cellular NF-KB activity by blocking ubiquitination mediated proteasomal degradation of IkBa in human hepatoma cells
}

\author{
Milan Surjit ${ }^{2}$ Bhavna Varshney ${ }^{1}$ and Sunil K Lal ${ }^{1 *}$
}

\begin{abstract}
Background: Nuclear factor kappa B (NF-kB) is a key transcription factor that plays a crucial role in host survival during infection by pathogens. Therefore, it has been a priority of many pathogens to manipulate the cellular NF-kB activity in order to create a favorable environment for their survival inside the host.

Results: We observed that heterologous expression of the open reading frame 2 (ORF2) protein in human hepatoma cells led to stabilization of the cellular I kappa B alpha (IKBa) pool, with a concomitant reduction in the nuclear localization of the p65 subunit of NF-KB and inhibition of NF-KB activity. Although basal or TPA induced phosphorylation of IKBa was not altered, its ubiquitination was markedly reduced in ORF2 expressing cells. Further analysis revealed that ORF2 protein could directly associate with the F-box protein, beta transducin repeat containing protein ( $\beta T R C P)$ and ORF2 over expression resulted in reduced association of IKBa with the SKP1 and CUL1 components of the SCF ${ }^{\beta T R C P}$ complex. Chromatin immunoprecipitation (ChIP) assay of the proximal promoter regions of MHC-I heavy chain and IL-8 genes using p65 antibody and LPS stimulated ORF2 expressing cell extract revealed decreased association of p65 with the above regions, indicating that ORF2 inhibited p65 binding at endogenous promoters.
\end{abstract}

Conclusions: In this report we suggest a mechanism by which ORF2 protein of HEV may inhibit host cell NF-KB activity during the course of a viral infection.

\section{Background}

Nuclear factor kappa B (NF-kB) is a crucial transcription factor regulating multiple cellular pathways leading to survival or death of the cell depending on the stimulus. In unstimulated cells, the NF-kB dimers (p50/p65 heterodimer or $\mathrm{p} 50 / \mathrm{p} 50$ homodimer) are retained in the cytoplasm in an inactive form as a consequence of their association with members of another family of proteins called I kappa B (IкB). Upon stimulation by activators like tumor necrosis factor alpha (TNF- $\alpha$ ), interleukin 1 (IL-1), CD40L, lipopolysaccharides (LPS) etc., signaling cascades involving activation of various protein kinases are initiated that result in the recruitment and activation of the IкB kinases (IKKs)

\footnotetext{
* Correspondence: sunilklal@icgeb.res.in

${ }^{1}$ Virology Group, International Centre for Genetic Engineering \& Biotechnology, New Delhi 110067, India

Full list of author information is available at the end of the article
}

which phosphorylate IкB $\alpha$, leading to its degradation by the $26 \mathrm{~S}$ proteasome complex. The degradation of ІкB $\alpha$ exposes the p50/p65 nuclear localization sequence and allows NF- $\mathrm{kB}$ dimers to translocate to the nucleus, bind to $\kappa \mathrm{B}$ motifs in the promoters regions of many genes, and regulate their transcription [1].

In many cases, infection by extra-cellular pathogens has been shown to alter NF-kB activity in order to facilitate the survival of pathogens or host. As part of the host defense mechanism against invading pathogens, NF- $\mathrm{KB}$ activation is required for resistance to a variety of viral, bacterial, and parasitic infections [1]. However, many viruses such as HIV, exploit this property to their benefit by driving their gene expression through $\mathrm{kB}$ response elements located in their promoters [2]. On the contrary, many pathogens such as African swine fever virus, HIV-1 and cowpox virus [3-5] have developed strategies to 
interfere with host NF- $\mathrm{kB}$ responses. Inhibition of NF- $\mathrm{kB}$ activity by these pathogens has been shown to be important for pathogenesis.

Hepatitis E virus (HEV) is a positive strand RNA virus which codes for three known open reading frames (ORFs) [6]. ORF1 codes for non structural proteins, essential for viral replication; ORF2 codes for the major capsid protein of HEV, called ORF2 protein; and ORF3 codes for a phosphoprotein which may play a key role in manipulating various host-cell processes during viral infection, and may have a role in cell survival and propagation of the virus $[7,8]$. Although HEV infection is generally self-limiting, it induces fulminant hepatic failure, which results in a very high mortality rate in pregnant women. A recent study done by Prusty and coworkers has demonstrated that NF- $\mathrm{kB}$ activity is suppressed in the PBMC and liver biopsy samples of pregnant fulminant hepatic failure patients [9]. However, the mechanism underlying this phenomenon remains unknown.

In the present study, we report the ability of the ORF2 protein to inhibit the cellular NF-KB activity. In human hepatoma cells, ORF2 protein could directly associate with the F-box protein $\beta$ TRCP and heterologous expression of the ORF2 protein led to reduced recruitment of SKP1 and CUL1 subunits to the SCF ${ }^{\beta T R C P}$ ubiquitination complex, resulting in decreased ubiquitination and degradation of the IкB $\alpha$ protein. This, in turn, led to reduced nuclear localization and subsequent DNA binding of the p65 protein, which is the major subunit of the NF- $\kappa B$ trans-activation complex. Analysis of two NF- $\kappa B$ target genes further confirmed the above observation. The possible significance of this phenomenon in enhancing survival of HEV infected hepatocytes is discussed.

\section{Results}

\section{Heterologous expression of the ORF2 protein inhibits NF-KB activity}

In order to test whether ORF2 or ORF3 protein of HEV inhibit cellular NF- $\mathrm{kB}$ activity, a reporter vector with IL-2 receptor promoter region, which contains NF- $\mathrm{kB}$ element, cloned upstream of the chloramphenicol acetyl transferase coding sequence (NF-kB CAT; [10] was used. This vector was inducible by NF- $\kappa B$ activating agents like TPA or IL-1 $\beta$. Huh7 cells were transiently transfected with the NF- $\mathrm{kB}$ CAT vector along with either ORF2 or ORF3 expression plasmids. Assay of chloramphenicol acetyl transferase (CAT) activity using these cell extracts revealed that ORF2 protein inhibited the NF- $\kappa B$ CAT activity (Figure 1A). However, no inhibition was observed by ORF3 expression (Figure 1A). In order to investigate whether ORF2 mediated inhibition of NF-kB activity was an artifact of the experimental system, cells were treated for 30 minutes with Phorbol 12-myristate 13-acetate (TPA), a known inducer of NF- $\mathrm{kB}$ activity [11], or

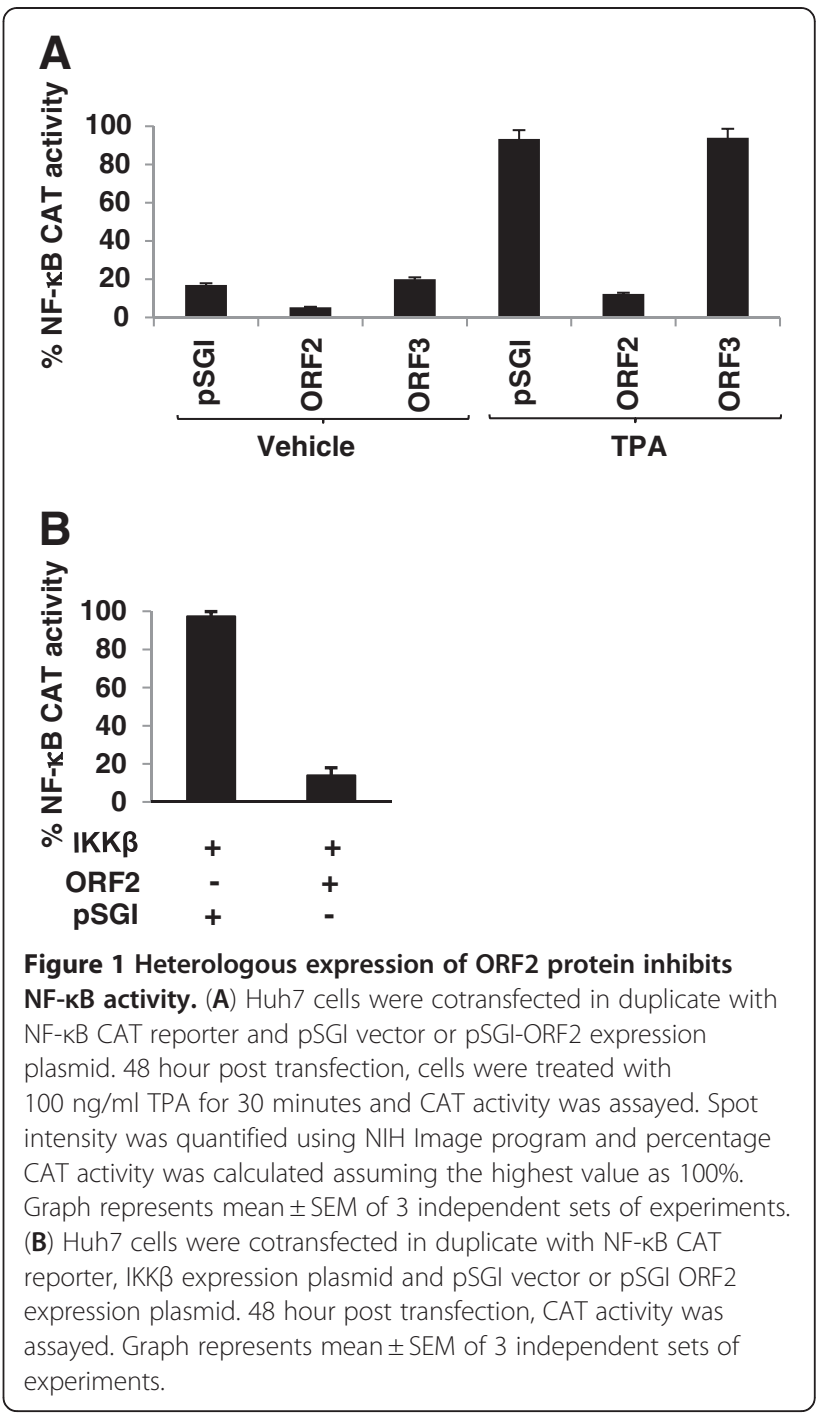

transfected with an expression construct of ІкB kinase $\beta$, which is the catalytic subunit of the IKK complex that acts as a constitutively active inducer of NF- $\mathrm{kB}$ activity [12]. TPA treatment increased NF- $\mathrm{kB}$ activity of mock transfected cells by approximately 4 folds whereas ORF2 expressing cells did not show any significant increase in NF- $\kappa B$ activity (Figure 1A). Similarly, co-expression of ORF2 in IKK $\beta$ transfected cells resulted in downregulation of NF- $\mathrm{KB}$ activity in comparison to cells transfected with only IKK $\beta$ (Figure 1B). These results clearly suggest that HEV ORF2 inhibits NF-kB activity.

Further, we examined the turnover of ІкB $\alpha$ in IKK $\beta$ and ORF2 co-expressing cells since IKB $\alpha$ is the major inhibitor of NF- $\mathrm{kB}$ activity in unstimulated cells. By performing a pulse chase assay, using $\left[{ }^{35} \mathrm{~S}\right]$-cys/met labeling mix, the half-life of ІкB $\alpha$ in IKK $\beta$ expressing cells was found to be approximately 90 minutes, whereas in cells expressing both IKK $\beta$ and ORF2, approximately $15 \%$ of 


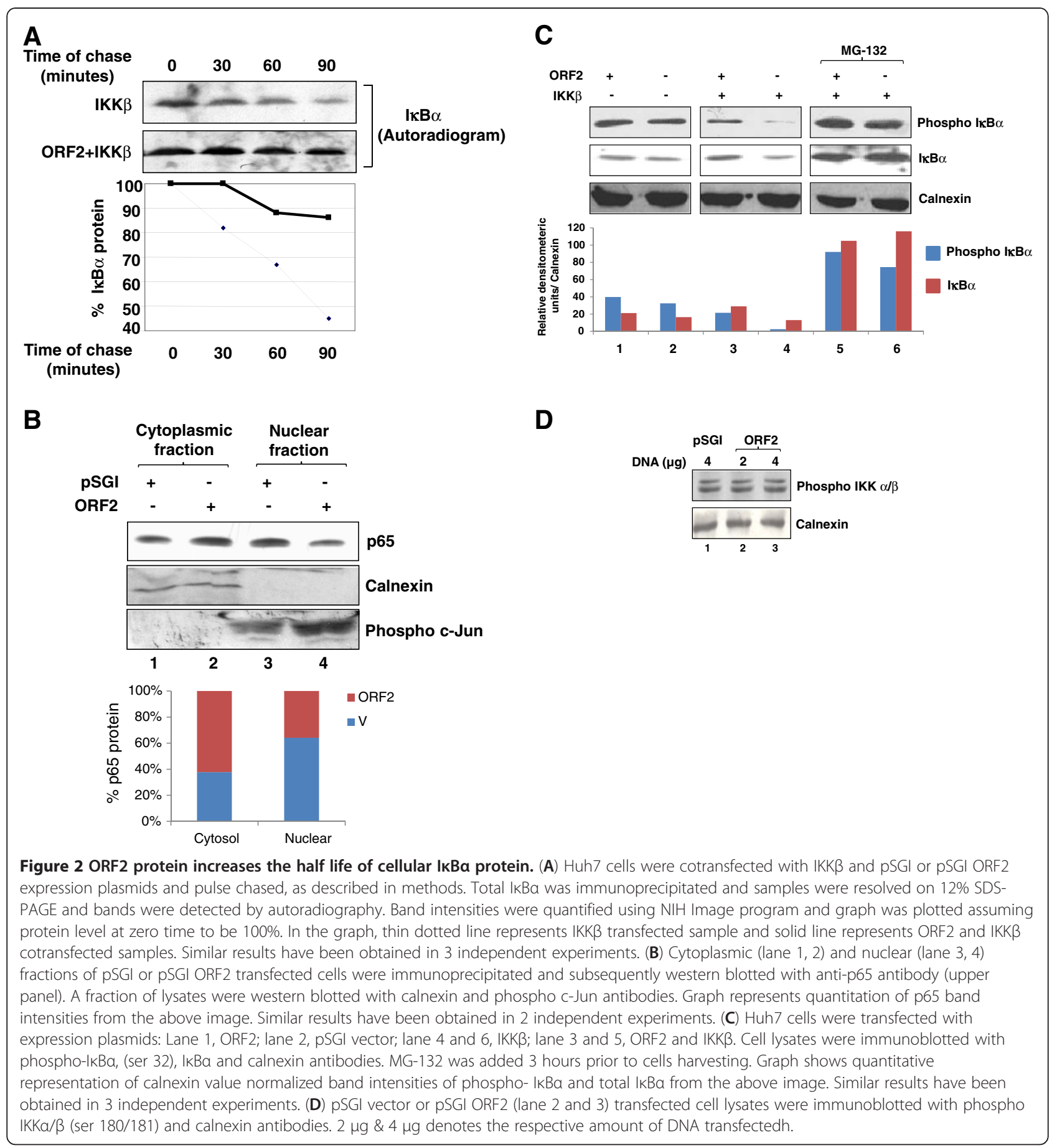

I $\mathrm{B} \alpha$ was found to be degraded at a chase period of 90 minutes (Figure 2A). Notably, the levels of IKB $\alpha$ at the end of the labeling period ( 0 minute chase) in IKK $\beta$ alone expressing cells were less than that in IKK $\beta$ and ORF2 coexpressing cells, indicating that $\mathrm{I} \kappa \mathrm{B} \alpha$ is a very labile protein in IKK $\beta$ expressing cells. The graph represents quantitative measurement of band intensities of $I_{\kappa} B \alpha$ at the indicated time points assuming the band intensity at the onset of the chase as $100 \%$. To further confirm whether I $\mathrm{K} B \alpha$ stabilization actually blocked nuclear translocation of NF-kB in ORF2 expressing cells, nuclear and cytoplasmic fractions were separated in mock and ORF2 transfected cells and equal amounts of samples were immunoprecipitated with anti-p65 antibody. As seen in Figure 2B, ORF2 transfected cells were found to accumulate more p65 protein in the 
cytoplasmic fraction than in the nuclear fraction (Figure 2B, lane 2 and 4; see the densitometric estimation of band intensities in the graph below). As expected, mock transfected cells were found to contain more p65 protein in the nuclear fraction (Figure 2B, lane 1 and 3). This is attributed to the fact that basal NF-kB activity is higher in Huh7 cells [13]. In order to check the purity of fractions obtained in nuclear and cytoplasmic fractions and as loading controls, equal amounts of both fractions from each sample were immunoblotted with anti-calnexin and anti-phospho c-Jun antibodies.

In order to check whether the phosphorylation of $\operatorname{IkB} \alpha$ was altered in ORF2 expressing cells, the level of phosphorylated IkB $\alpha$ (ser32) was measured in ORF2 expressing cells. ORF2 expression marginally increased the levels of phospho IkB $\alpha$ (Figure 2C, upper panel, lane 1 and 2; see the densitometric estimation of band intensities in the

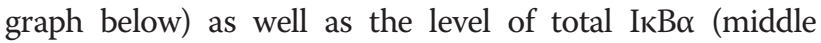
panel, lane 1 and 2). In IKK $\beta$ and ORF2 co-expressing cells, the level of total as well as phosphorylated IкB $\alpha$ was significantly higher as compared to only IKK $\beta$ expressing cells (Figure $2 \mathrm{C}$, lane 3 and 4 ). In order to check that the decreased band intensity in IKK $\beta$ expressing cells was due to accelerated degradation of $\mathrm{I} \kappa \mathrm{B} \alpha$, one set of cells were also treated with the proteasome inhibitor MG-132 for 2 hours, resulting in equal $\mathrm{I}_{\kappa} \mathrm{B} \alpha$ protein levels in both the samples (Figure $2 \mathrm{C}$, lane 5 and 6). Aliquots of the sample were immunoblotted with anti-calnexin antibody to check equal loading. Thus, it appears that ORF2 expression prevents the degradation of IKB $\alpha$. The fact that ORF2 did not interfere with phosphorylation of I $\mathrm{KB} \alpha$ by the IKK complex was further confirmed by checking the activity of the IKK complex. ORF2 expressing cell lysate was immunoblotted for phospho IKK $\alpha / \beta$ (ser180/181) levels. As expected, ORF2 expression (2 or $4 \mu$ g plasmid DNA transfection) did not modulate the levels of pIKK $\alpha / \beta$ (Figure 2D).

\section{ORF2 protein interferes with ІКBa ubiquitination}

Proteasomal degradation of $I \kappa B \alpha$ is preceded by its ubiquitination, which occurs by the association of phosphorylated $I_{\kappa B} \alpha$ with the SCF ${ }^{\beta T R C P}$ complex [14]. In order to check whether ORF2 inhibits $I \kappa B \alpha$ ubiquitination, we checked the level of ubiquitinated IKB $\alpha$ in ORF2 expressing cells. Mock or ORF2 transfected cells were treated with MG-132 for 2 hours, IkB $\alpha$ was immunoprecipitated, followed by immunblotting with anti-ubiquitin antibody. Protein level of ubiquitinated $\mathrm{I} \kappa \mathrm{B} \alpha$ was significantly decreased in full-length ORF2 expressing cells as compared to control cells (Figure 3A top panel, lane 1 and 2). A similar effect (lane 3) was observed following expression of a mutant ORF2 protein $(\Delta 35)$ with ER signal sequence deleted which consequently constitutively localizes to the cytoplasm [15]. Aliquots of the immunoprecipitated lysate were immunoblotted with $\mathrm{I} \kappa \mathrm{B} \alpha$ antibody to confirm its presence (Figure 3A, middle panel). A parallel set of samples were labeled with $\left[{ }^{35} \mathrm{~S}\right]$-cys/met promix, immunoprecipitated with anti-ORF2 antibody and autoradiographed to check the expression of full-length and $\triangle 35$ ORF2 protein (Figure 3A, bottom panel).

Subsequently, we checked whether ORF2 interfered with the assembly of IkB $\alpha$ ubiquitination machinery. Expression of ORF2 protein inhibited the association of IKB $\alpha$ with SKP1 (Figure 3B, top panel) and CUL1 (Figure 3B, $2^{\text {nd }}$ panel) in a dose-dependent manner (compare lane 1 with lanes 2 and 3). Aliquots of the sample were immunoblotted with anti-IkB $\alpha$ antibody to check the levels of IkB $\alpha$ ( $3^{\text {rd }}$ panel). A parallel set of samples were labeled with $\left[{ }^{35} \mathrm{~S}\right]$-cys/met and immunoprecipitated with anti-ORF2 antibody to check the expression of ORF2 (Figure 3B, $4^{\text {th }}$ panel). To further check whether the ORF2 expression in these cells inhibited the association of IkB $\alpha$ with the F-box protein $\beta$ TRCP, ORF2 and myc tagged $\beta$ TRCP coexpressing cells were labeled with $\left[{ }^{35} \mathrm{~S}\right]$-cys/met and aliquots of the lysate were immunoprecipitated with antimyc antibody and immunoblotted using anti-IkB $\alpha$ antibody. ORF2 expression led to the inhibition of IкB $\alpha$ association with full-length $\beta$ TRCP when compared to control cells (Figure 3C, lane 3 and 2, respectively). However, I $\mathrm{B} \alpha$ association with an F-box deleted mutant $\beta$ TRCP $(\triangle \mathrm{F}-\beta \mathrm{TRCP})$ remains unaffected despite the presence of ORF2 (Figure 3C, lane 5). The same blot was stripped and reprobed with anti-myc antibody to check the expression of full-length and $\triangle F-\beta T R C P$ (Figure $3 C$, lower panel, lane $1-5)$. Lane 1 shows the protein level of total $\mathrm{I} \kappa \mathrm{B} \alpha .50 \%$ of the sample has been loaded in lane 1 in comparison to other samples. The other half of the blot was autoradiographed to check the expression of the ORF2 protein (Figure 3C, lower panel, lane 6-8).

Since the presence of ORF2 could inhibit IkB $\alpha$ association with full-length $\beta$ TRCP but not with $\triangle \mathrm{F}-\beta \mathrm{TRCP}$, we postulated that the ORF2 protein either interacts with IKB $\alpha$ and sequesters it away from $\beta$ TRCP or interacts with other subunits of the SCF complex thereby modulating $\beta$ TRCP binding to $\mathrm{I} \kappa \mathrm{B} \alpha$. Alternatively, it binds to $\beta$ TRCP itself and blocks the formation of the SCF complex. We thus checked the association of ORF2 with the above components. No interaction was detected between ORF2 and IkB $\alpha$ (Figure 3C, lane 6) as judged by coimmunoprecipitation assay. The possibility that $\beta$ TRCP over-expression might be promoting ORF2 association with $\mathrm{I} \kappa \mathrm{B} \alpha$ was ruled out by testing ORF2 and $\mathrm{I} \kappa \mathrm{B} \alpha$ association in full-length or $\triangle \mathrm{F}-\beta \mathrm{TRCP}$ overexpressing cells (Figure 3D, lane 7 and 8). Lane 1 shows the level of $\mathrm{I} \kappa \mathrm{B} \alpha$ in control cells. Subsequently, we checked whether ORF2 interacts with SKP1 and CUL1. The ORF2 protein did not associate with either SKP1 or CUL1 (Figure 3D, lane 1 and 2) under conditions, where IKB $\alpha$ associated with these proteins (lane 3). 


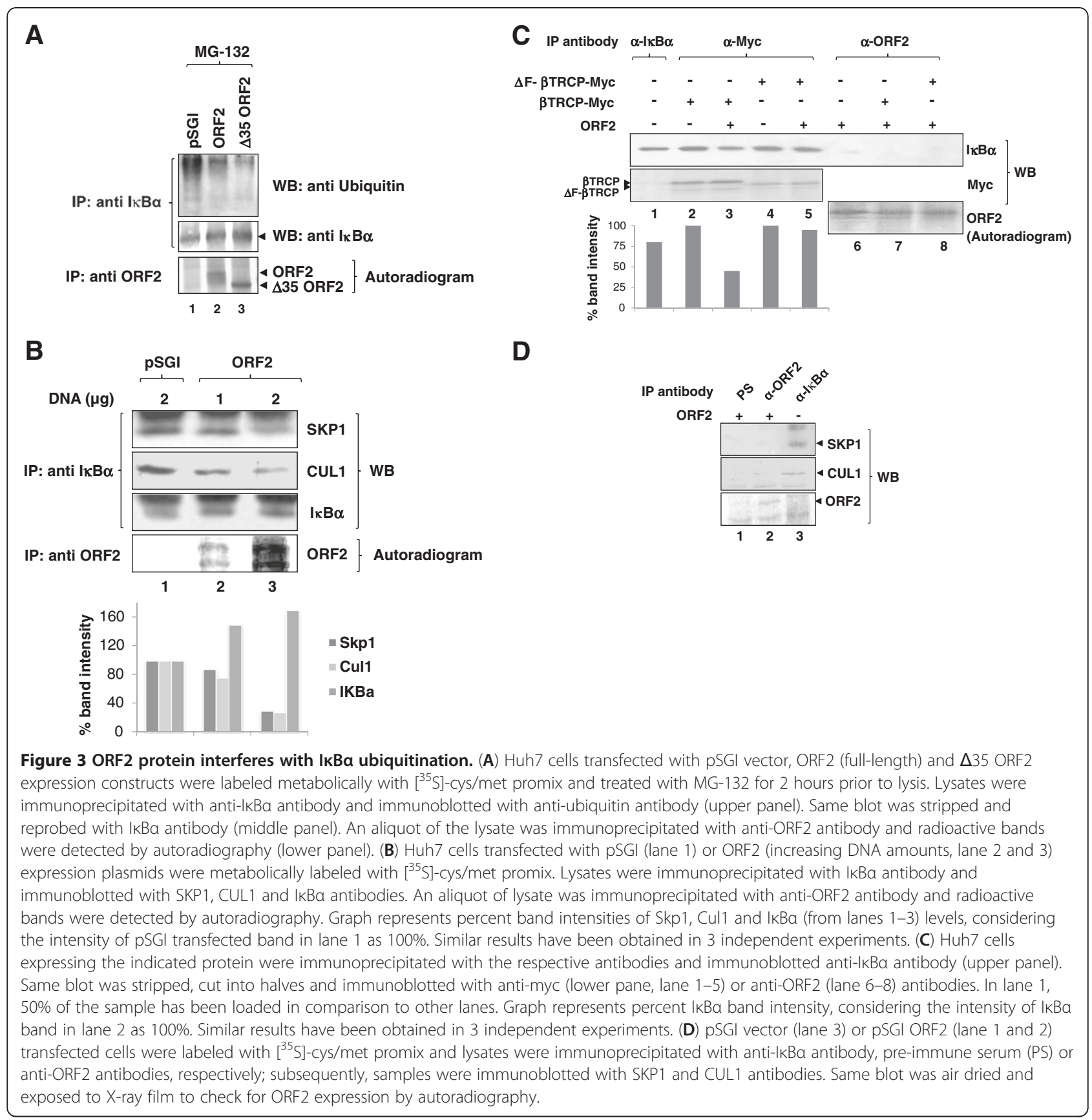

\section{ORF2 protein directly associates with the F-box protein BTRCP}

Coimmunoprecipitation assay of cell lysate expressing both ORF2 and myc tagged full-length $\beta$ TRCP revealed that ORF2 could efficiently associate with the latter (Figure 4A, upper panel, lane 2). Exposure of the same blot to X-ray film revealed the band specific to ORF2 in $\beta$ TRCP and ORF2 cotransfected cells (Figure 4A, lower panel, lane 2). $3^{\text {rd }}$ lane in upper panel shows the expression of the $\beta$ TRCP protein, as judged by immunoprecipitation using anti-myc antibody. Specificity of the above interaction was further verified by checking for association of ORF2 with another F-box protein, SKP2. We were unable to detect any interaction between ORF2 and SKP2 as judged by coimmunoprecipitation assay (Figure 4B, top panel). In order to ensure that SKP2 was indeed functional in these experiments, the same blot was stripped and reprobed with anti-myc antibody. Endogenous SKP2 was able to coprecipitate endogenous as well as overexpressed c-myc protein (Figure 4B, middle panel) and similarly IP using myc antibody revealed its interaction with the SKP2 protein (Figure 4B, lane 4, 
A

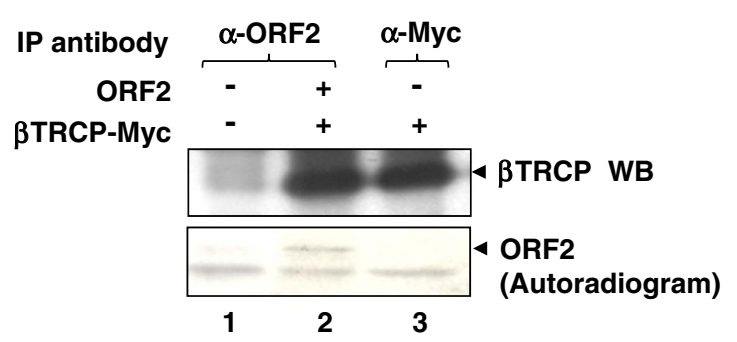

B

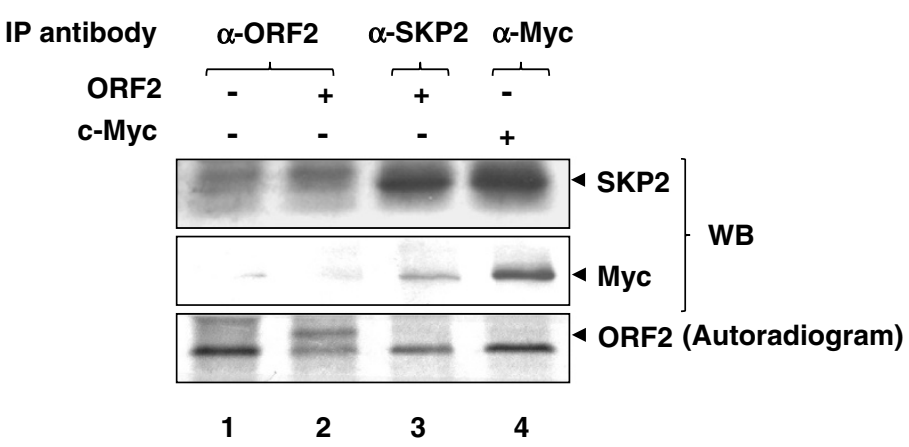

\section{IP antibody}

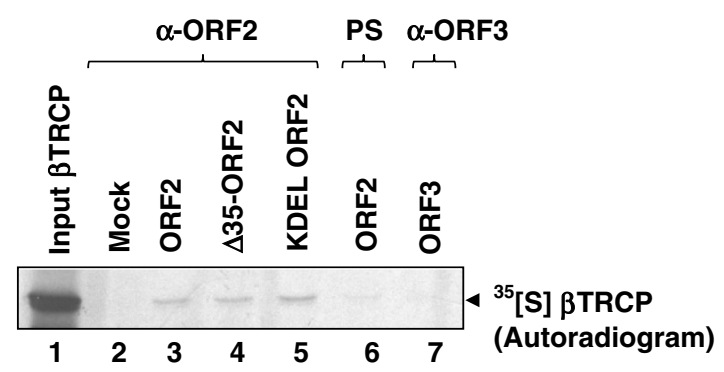

Figure 4 ORF2 protein associates with $\beta$ TRCP protein. (A) Huh7 cells were transfected with PSGl, ORF2 and myc tagged $\beta$ TRCP expression constructs in indicated combinations and labeled with $\left[{ }^{35} \mathrm{~S}\right]$-cys/met promix. Lysates were immunoprecipitated with anti-ORF2 (lane 1 and 2) or anti-Myc (lane 3) antibody and immunoblotted with anti-Myc antibodies. Immunoblot presented in upper panel was air dried and exposed to X-ray film to check for ORF2 expression (lower panel). (B) Huh7 cells transfected with pSGl vector or ORF2 or c-Myc expression constructs were labeled with $\left.{ }^{35} \mathrm{~S}\right]$-cys/met promix, immunoprecipitated with the indicated antibodies and immunoblotted with anti-SKP2 or anti-Myc antibodies. Myc blot was air dried and exposed to X-ray film to check for ORF2 expression ( $3^{\text {rd }}$ panel). (C) Lysates from mock (lane 2), ORF2 (lane 3 and 6), $\triangle 35$ ORF2 (lane 4) and KDEL ORF2 (lane 5) transfected Huh7 cells, were immunoprecipitated using anti-ORF2 antibody (lane 2-5) or pre-immune serum (PS, lane 6) and incubated along with in vitro translated $\left.{ }^{35} \mathrm{~S}\right]$-cys/met labeled full-length $\beta$ TRCP protein (lane 2-6). Bound $\beta$ TRCP protein band was visualized by autoradiography. Lane 1 represents total $\beta$ TRCP protein used in each sample. For negative control, ORF3 expressing cells were immunoprecipitated with anti-ORF3 antibody and processed as above (lane 7).

upper and middle panels). Bottom panel shows an autoradiogram of ORF2 expression. These experiments proved that ORF2 specifically interacts with the F-box protein $\beta$ TRCP. Direct interaction between ORF2 and $\beta$ TRCP was further confirmed using an in vitro pulldown assay. Full-length ORF2 as well as KDEL ORF2 (ORF2 protein containing "KDEL" amino acids at its C-terminal end, which allows it to be retained in the endoplasmic reticulum instead of getting transported through the golgi) and $\triangle 35$ ORF2 mutant were able to pull-down BTRCP (Figure 4C, lane 3, 4, 5). As negative controls, ORF2 transfected sample was immunoprecipitated with pre-immune serum (Figure 4C, lane 6) or mock translated lysate was incubated with ORF2 protein bound to beads (Figure 4C, lane 2) or, the ORF3 protein was incubated with $\beta$ TRCP protein (Figure $4 \mathrm{C}$, lane 7 ).

\section{The ORF2 protein downregulates the expression of NF-KB targets}

NF- $\mathrm{kB}$ is known to regulate the transcription of a large number of genes during different cellular conditions. One of the most critical events for initiation of immune response against viral antigens is the presentation of viral peptide epitopes over the infected cell surface, 
which can then be recognized by cytolytic $\mathrm{T}$ cells. The viral antigens are presented through their association with the major histocompatibility complex-I (MHC-I). As MHC-I heavy chain is a known target of NF- $k B$, we checked expression levels of the MHC-I heavy chain in ORF2 expressing cells stimulated with bacterial lipopolysacharides (LPS). EGFP (Figure 5A, lane 1), full-length ORF2 (Figure 5A, lane 2) or $\triangle 35$-ORF2 (Figure 5A, lane 3) transfected cells were treated with LPS for 45 minutes and total cell lysate was immunoprecipitated and immunoblotted with anti-MHC-I heavy chain antibody (Figure 5A, upper panel). Protein level of MHC-I heavy chain was decreased in both full-length and $\triangle 35$-ORF2 expressing cells in comparison to EGFP expressing cells. An aliquot of the lysate was immunoblotted with anti-calnexin antibody to ensure equal loading of the sample (lower panel).

Further, we checked NF-kB recruitment to the MHC I heavy chain promoter in LPS stimulated ORF2 expressing cells by chromatin immunoprecipitation (ChIP) assay. Immunoprecipitation was conducted using an antibody specific for the p65 subunit of the NF-kB complex. EGFP expression did not alter p65 recruitment to MHC-I heavy chain promoter. However, full-length or $\triangle 35$-ORF2 expression decreased p65 recruitment to the MHC-I heavy chain promoter. $10 \%$ of the total lysate used for one immuonprecipitation reaction was used as input in each sample (Figure 5B, upper panel). We also checked p65 recruitment to interleukin 8 (IL-8) proximal promoter region, which showed a similar pattern as observed for the MHC-I heavy chain promoter (Figure 5B, lower panel). As a control to check whether the observed phenomenon was specific for NF- $k B$, aliquots of the LPS treated lysate were immunoprecipitated with anti-SP1 antibody (specific for SP1 transcription factor, which also binds to MHC-I heavy chain promoter) and purified ChIP DNA was PCR amplified using MHC-I heavy chain promoter specific primer. As expected, SP1 recruitment to the MHC-I heavy chain promoter was not altered in ORF2 expressing cells (Figure 5C). These experiments confirmed that ORF2 expression specifically prevents p $65 \mathrm{NF}-\mathrm{kB}$ association with its cognate response element present on natural promoters.

Next, the effect of ORF2 protein on the expression of two TPA inducible cytokines- IL- 6 and IL- 8 was measured by performing real time quantitative RT-PCR of these cytokine transcripts in ORF2 expressing Huh7 cells, which were treated with TPA for 6 hours prior to RNA isolation. As expected, IL-6 and IL-8 transcript level was decreased in

ORF2 expressing TPA treated cells in comparison to mock transfcetd TPA treated cells (Figure 5D). These experiments indicates that ORF2 protein, by virtue of its ability to inhibit NF- $\mathrm{kB}$ activity, suppress TPA induced IL-6 and IL-8 RNA synthesis.

\section{Discussion}

The ORF2 protein of HEV has traditionally been believed to associate with genomic RNA, multimerize and form the viral capsid. No other function of ORF2 protein has yet been reported. In this article, we present evidence which suggest that the ORF2 protein may be playing an important regulatory role during the viral life cycle. The fact that the observed phenomenon was not an artifact of the experimental setup was evident from multiple experiments. First, ORF2 was capable of directly interacting with the F-box protein $\beta$ TRCP, both in vitro and in vivo. Second, $\triangle 35$ ORF2 mutant that is unable to translocate to the endoplasmic reticulum (ER), was also capable of inhibiting NF- $\mathrm{kB}$ activity, thus ruling out the possibility of ER stress induced artifact. Third, ORF3 protein of HEV was unable to elicit such a function in parallel experiments.

HEV infection results in an acute, self-limiting and icteric disease that is prevalent in much of the developing world. Although self-limiting infection occurs in adults with mortality rate $\sim 1-2 \%$, a high $10-20 \%$ mortality rate is observed during pregnancy [6]. Hence it is important to understand the molecular mechanism by which HEV completes its life cycle inside the host. A recent study done by Prusty and coworkers revealed that NF- $\mathrm{KB}$ activity is inhibited in the PBMC and liver of fulminant hepatic failure patients [9]. Our findings that the ORF2 protein has the ability to inhibit NF-kB activity in human hepatoma cells provide a possible molecular explanation to their observation.

The NF-KB inhibitory activity of the ORF2 protein may be mediated by its ability to directly associate with the F-box protein $\beta$ TRCP and inhibit the assembly of the IкB $\alpha$ ubiquitination complex. $\beta$ TRCP is a cytoplasmic protein. Hence it is worth speculating that the ORF2 $\beta$ TRCP interaction would occur in the cytoplasm. Although ORF2 is an N-linked glycoprotein, which is cotranslationally translocated to the endoplasmic reticulum, recent studies performed in our laboratory have demonstrated that a fraction of ORF2 protein exploits the ER retro-translocation machinery to get access to the cytoplasm, where it is detected as a non-glycosylated protein. Importantly, in contrast to other retrotranslocated substrates, retrotranslocated ORF2 protein is not immediately degraded by the $26 \mathrm{~S}$ proteasome complex present in the cytoplasm [16]. Thus, cytoplasm localized deglycosylated ORF2 protein may be able to associate with $\beta$ TRCP. Indeed, experiments done using $\Delta 35$ ORF2 protein suggest that non-glycosylated, cytoplasm localized ORF2 protein is capable of associating with $\beta$ TRCP and inhibiting NF- $\mathrm{kB}$ activity. Further studies need to be undertaken to verify the exact mechanism.

Expression of MHC class I heavy chain, which is known to be a transcriptional target of NF- $\mathrm{kB}$, was down-regulated in LPS treated ORF2 expressing cells presumably due to reduced promoter occupancy of p65, 
A

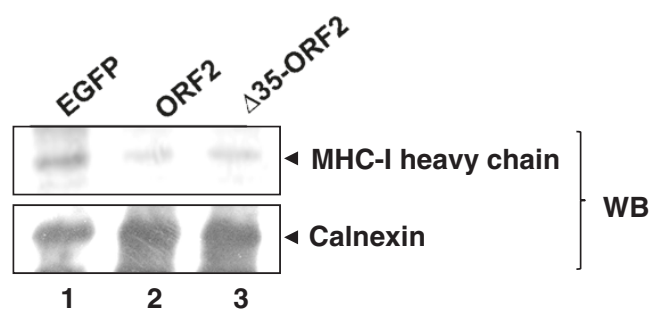

B

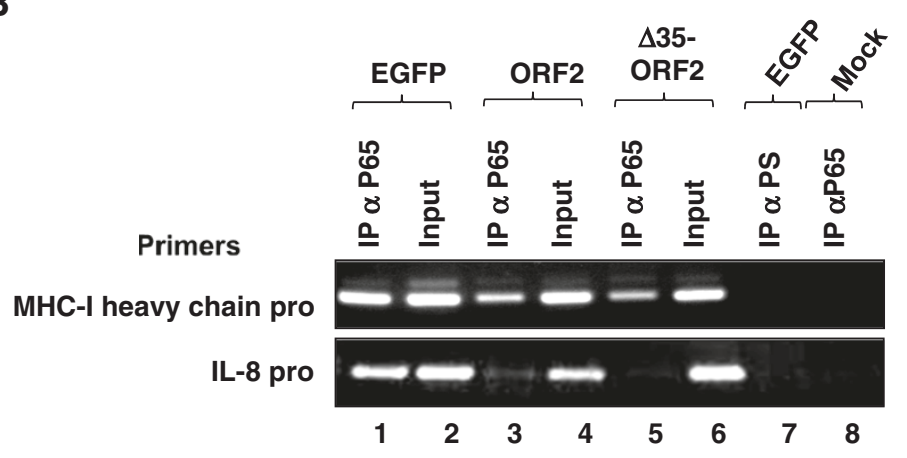

C

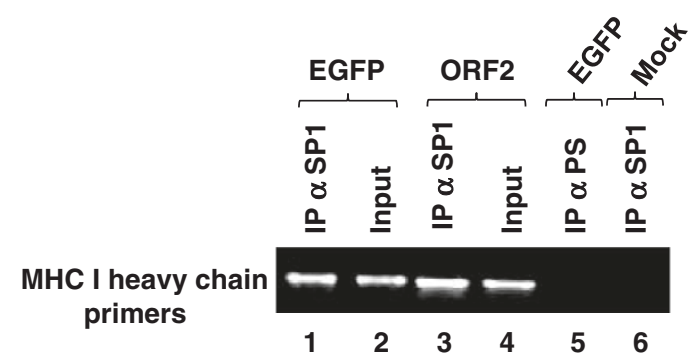

D
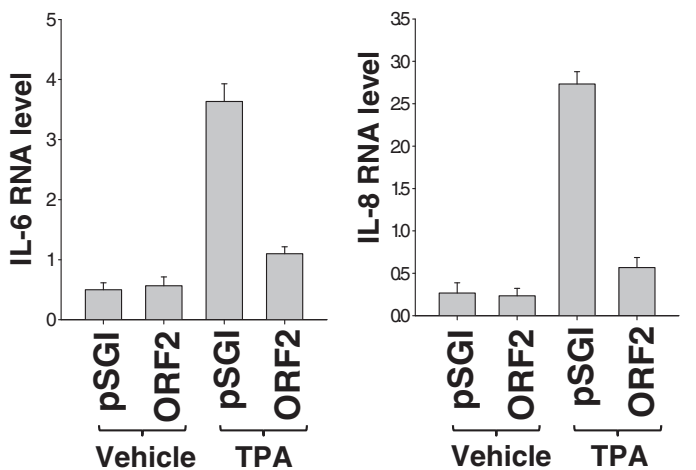

Figure 5 ORF2 protein inhibits the expression of MHC-I heavy chain. (A) EGFP, ORF2 or $\triangle 35$ ORF2 expressing cells were treated with LPS for 45 minutes after 48 hours of transfection. Lysates were immunoprecipitated and immunoblotted with anti-MHC-I heavy chain antibody (upper panel). An aliquot of the lysate was immunoblotted with anti-calnexin antibody (lower panel). (B) To test p65 NF-KB binding to the MHC-I heavy chain and IL-8 promoters ChIP assay was performed. Huh7 Cells were transfected with EGFP, ORF2 or $\triangle 35$ ORF2 expression plasmids and treated with LPS for 45 minutes prior to harvesting. PCR was performed using primers flanking the proximal promoter region of MHC-I heavy chain and IL-8 genes. Lane 7 shows ChIP from EGFP expressing cells immunoprecipitated with rabbit pre-immune serum. Lane 8 shows ChIP from mock immuonprecipitation (without cell lysate) using p65 antibody. 10\% of the initial amount of chromatin used for one immuonprecipitation assay was used as input in each PCR. (C) SP1 binding to the MHC-I heavy chain ptomoter was again assayed by ChIP. Huh7 Cells were transfected with EGFP or full-length ORF2 expression plasmids and treated with LPS for 45 minutes prior to harvesting. PCR for MHC-I promoter regions was performed using primers mentioned above. Lane 5 shows ChIP from EGFP expressing cells immunoprecipitated with rabbit pre-immune serum. Lane 6 shows ChIP from mock immunoprecipitation using SP1 antibody. 10\% of the initial amount of chromatin used for one immuonprecipitation assay was used as input in each PCR. (D) Quantitative RT-PCR analysis of IL-6 and IL-8 RNA level in Huh7 cells, treated as indicated. Values were normalized with respect to that of HPRT and represented as mean \pm SEM. 
which is crucial for NF-KB dependent transcriptional activation. In an infected cell, by default, pathogenic antigens are processed by the proteasome and presented by the MHC class I molecules so that the former can be recognized by cytolytic $\mathrm{T}$ cells. This helps in pathogen clearance at an early stage of infection. Thus, it is beneficial for any pathogen to escape this step. In fact, downregulation of MHC class I both at transcriptional and post-translational level is observed in many pathogenic infections [17-19]. Since NF- $\mathrm{kB}$ is one of the major transcription factors induced during pathogen infection that enhances gene expression of many chemokines and class I molecules in the infected cell, inhibition of the NF- $\mathrm{kB}$ activity by pathogen encoded proteins will ensure evasion of host immune response at an early stage; thus providing the pathogen a time window to establish successful infection.

\section{Conclusions}

Owing to its central role in regulating multiple cell signaling pathways, modulation of NFKB activity has been an attractive target of many viral factors in order to allow them to exploit the host cell signaling machinery to their benefit. We have identified the ability of the ORF2 protein of the HEV to inhibit host cell NFKB activity. However, whether such an event is recapitulated during the natural course of HEV infection and whether it is crucial for the virus induced pathogenic effects, can be answered only by performing similar experiments using a model organism infected with the wild type virus. Nevertheless, the present study confirms the NFKB inhibitory property of the HEV ORF2 protein and provides some evidence suggesting a plausible mechanism underlying this event.

\section{Methods}

\section{Plasmids and reagents}

Cloning of ORF2 and $\triangle 35$ ORF2 in pSGI has been described earlier [15]. Flag tagged IKK $\beta$ [12], IL-2 receptor $\alpha$ promoter containing NF- $\mathrm{kB}$ response element cloned upstream of the chloramphenicol acetyl ransferase (CAT) coding sequence (NF-kB CAT) [10], Wildtype, $\triangle \mathrm{F} \beta$ TRCP cDNA in pCDNA3.1 [20] and pSGI c-myc [21] constructs were gifts from Drs. Rene Bernards, Ranjan Sen, Richard Benarous and Vijay Kumar, respectively. All DNA constructs used for mammalian cell transfection were purified by cesium chloride gradient centrifugation [22].

All antibodies were purchased from Santa Cruz Biotechnology Inc. (California, USA); TPA and MG-132 were purchased from Calbiochem Chemicals (California, USA). LPS was purchased from Sigma-Aldrich (USA). $\left[{ }^{35} \mathrm{~S}\right]$-cysteine/methionine labeling mix was obtained from New England Nuclear (Massachusetts, USA).

\section{Cell culture and transfection}

Human Hepatoma (Huh7) cells were maintained in DMEM supplemented with penicillin, streptomycin and $10 \%$ fetal bovine serum. Cells were transfected with Lipofectin/Lipofectamine 2000 reagent (Invitrogen Corp., California, USA) as per manufacturer's instructions. For negative control conditions, cells were transfected with their respective empty vectors. In all transfections, total DNA amount was equalized by adding pSGI vector.

\section{Metabolic labeling, immunoprecipitation and immunoblotting}

Radiolabeling of cells with $\left[{ }^{35} \mathrm{~S}\right]$-cys/met promix, immunoprecipitation and immunoblotting was done as described earlier [8]. Data obtained is representative of at least 3 independent sets of experiments conducted. Results were quantified using the NIH Image V: 1.32 program, normalized values calculated and graphs plotted wherever indicated. All the inhibitors were added during starvation period and maintained throughout the labeling period.

Effective concentrations of different compounds used: TPA 100 ng/ml, MG-132 $50 \mu \mathrm{M}$, LPS $10 \mu \mathrm{g} / \mathrm{ml}$.

\section{Pulse chase assay}

Cells were pulse-labeled for 20 minutes with $250 \mu \mathrm{Ci}$ of $\left[{ }^{35} \mathrm{~S}\right]$-cys/met labeling mix and chased in complete medium for the indicate time periods, followed by immunoprecipitation, as described before [23].

\section{Chloramphenicol acetyl transferase (CAT) assay}

Forty eight hours post-transfection, cells were harvested in phosphate buffer saline and CAT assay was conducted as described elsewhere [21].

\section{In vitro protein expression}

$\beta$ TRCP protein was expressed in-vitro using pCDNA$\beta T R C P$ expression construct in a coupled transcriptiontranslation reaction (TNT kit, Promega Corp., Wisconsin, USA) following manufacturers protocol.

\section{Nuclear fractionation}

Nuclear fractionation was performed as described earlier [23].

\section{Chromatin immunoprecipitation (ChIP) assay}

Cells cultured in $60 \mathrm{~mm}$ dish were transfected in triplicate with respective plasmids. Control samples were transfected with EGFP expression plasmid (pSGI-EGFP). Forty-eight hours post-transfection, cells were fixed in $1 \%$ formaldehyde and ChIP assay was performed as described elsewhere [24]. Forward and reverse primer sequences for amplification of MHC-I heavy chain promoter were 5 CAGGGAGT CCAGTTCAGGGA $3^{\prime}$ and $5^{\prime}$ TGAGTCCGGGTGGGTGC 
GTG $3^{\prime}$, respectively and for amplification of IL-8 promoter were $5^{\prime}$ GGGCCATCAGTTGCAAA TC $3^{\prime}$ and $5^{\prime}$ TTCCT TCCGGTGGTTTCTTC $3^{\prime}$, respectively.

\section{RNA isolation and real time quantitative RT-PCR analysis}

RNA was isolated from Huh7 cells using Trizol reagent (Invitrogen) following manufacturers protocol, followed by reverse transcription and real time quantitative RTPCR analysis as described [25].

\section{Authors' contributions}

MS contributed towards all the molecular biology work, transfection work and CAT and pulse-chase assays and acquisition of data and data analysis and interpretation BV contributed to the RNA based work and ChIP assays and revised the manuscript critically SKL was involved in conception and design drafting initial experiments and later the manuscript. Each author has participated sufficiently in the work to take public responsibility for appropriate portions of the content. All authors read and approved the final manuscript.

\section{Acknowledgements}

We are thankful to Drs. Richard Benarous, Ranjan Sen, Rene Bernards and Vijay Kumar for providing various plasmids as mentioned in Materials. We thank Ms. Chandrani Chakravarty for help with the manuscript. MS was supported by a research fellowship from the Council of Scientific and Industrial Research (CSIR), India. This work was supported by internal funds from ICGEB.

\section{Author details}

'Virology Group, International Centre for Genetic Engineering \& Biotechnology, New Delhi 110067, India. ${ }^{2}$ Translational Health Science and Technology Institute, 496, Udyog Vihar Phase III, Gurgaon 122016, India.

Received: 10 June 2011 Accepted: 14 March 2012

Published: 16 May 2012

\section{References}

1. Vallabhapurapu S, Karin M: Regulation and function of NF-kappaB transcription factors in the immune system. Annu Rev Immunol 2009, 27:693-733.

2. Roulston A, Lin R, Beauparlant P, Wainberg MA, Hiscott J: Regulation of human immunodeficiency virus type 1 and cytokine gene expression in myeloid cells by NF-kappa B/Rel transcription factors. Microbiol Rev 1995, 59:481-505.

3. Bour S, Perrin C, Akari H, Strebel K: The human immunodeficiency virus type 1 Vpu protein inhibits NF-kappa B activation by interfering with beta TrCP-mediated degradation of Ikappa B. J Biol Chem 2001, 276:15920-15928.

4. Oie KL, Pickup DJ: Cowpox virus and other members of the orthopoxvirus genus interfere with the regulation of NF-kappaB activation. Virology 2001, 288:175-187.

5. Revilla Y, Callejo M, Rodriguez JM, Culebras E, Nogal ML, Salas ML, Vinuela E, Fresno M: Inhibition of nuclear factor kappaB activation by a virusencoded IkappaB-like protein. J Biol Chem 1998, 273:5405-5411.

6. Panda SK, Jameel S: Hepatitis E virus: from epidemiology to molecular biology. Viral Hepatitis Rev 1997, 3:227-251.

7. Chandra V, Taneja S, Kalia M, Jameel S: Molecular biology and pathogenesis of hepatitis E virus. J Biosci 2008, 33:451-464.

8. Surjit M, Oberoi R, Kumar R, Lal SK: Enhanced alpha1 microglobulin secretion from Hepatitis E virus ORF3-expressing human hepatoma cells is mediated by the tumor susceptibility gene 101. J Biol Chem 2006, 281:8135-8142.

9. Prusty BK, Hedau S, Singh A, Kar P, Das BC: Selective suppression of NF-kBp65 in hepatitis virus-infected pregnant women manifesting severe liver damage and high mortality. Mol Med 2007, 13:518-526.

10. Pomerantz JL, Mauxion F, Yoshida M, Greene WC, Sen R: A second sequence element located 3 ' to the NF-kappa B-binding site regulates IL-2 receptor-alpha gene induction. J Immunol 1989, 143:4275-4281.
11. Rebois RV, Patel J: Phorbol ester causes desensitization of gonadotropinresponsive adenylate cyclase in a murine Leydig tumor cell line. J Biol Chem 1985, 260:8026-8031.

12. Brummelkamp TR, Nijman SM, Dirac AM, Bernards R: Loss of the cylindromatosis tumour suppressor inhibits apoptosis by activating NF-kappaB. Nature 2003, 424:797-801.

13. Qiao L, Zhang H, Yu J, Francisco R, Dent P, Ebert M, Rocken C, Farrell G: Constitutive Activation of NF-KB in Human Hepatocellular Carcinoma: evidence of a Cytoprotective Role. Hum Gene Ther 2006, 17:280-290.

14. Hayden MS, Ghosh S: Signaling to NF-kappaB. Genes Dev 2004, 18:2195-2224.

15. Zafrullah M, Ozdener MH, Kumar R, Panda SK, Jameel S: Mutational analysis of glycosylation, membrane translocation, and cell surface expression of the hepatitis E virus ORF2 protein. J Virol 1999, 73:4074-4082.

16. Surjit M, Jameel S, Lal SK: Cytoplasmic localization of the ORF2 protein of hepatitis $E$ virus is dependent on its ability to undergo retrotranslocation from the endoplasmic reticulum. J Virol 2007, 81:3339-3345.

17. Hazes B, Read RJ: Accumulating evidence suggests that several AB-toxins subvert the endoplasmic reticulum-associated protein degradation pathway to enter target cells. Biochemistry 1997, 36:11051-11054.

18. Jakob U, Muse W, Eser M, Bardwell JC: Chaperone activity with a redox switch. Cell 1999, 96:341-352.

19. Wiertz EJ, Jones TR, Sun L, Bogyo M, Geuze HJ, Ploegh HL: The human cytomegalovirus US11 gene product dislocates MHC class I heavy chains from the endoplasmic reticulum to the cytosol. Cell 1996, 84:769-779.

20. Margottin F, Bour SP, Durand H, Selig L, Benichou S, Richard V, Thomas D, Strebel K, Benarous R: A novel human WD protein, $\mathrm{h}$-beta $\operatorname{TrCp}$, that interacts with HIV-1 Vpu connects CD4 to the ER degradation pathway through an F-box motif. Mol Cell 1998, 1:565-574.

21. Kalra N, Kumar V: c-Fos is a mediator of the c-myc-induced apoptotic signaling in serum-deprived hepatoma cells via the p38 mitogenactivated protein kinase pathway. J Biol Chem 2004, 279:25313-25319.

22. Sambrook J, Fritsch EF, Maniatis T: Molecular Cloning: A Laboratory Manual. 2nd edition. NY: Cold Spring Harbor Laboratory; 1989.

23. Surjit M, Kumar R, Mishra RN, Reddy MK, Chow VT, Lal SK: The severe acute respiratory syndrome coronavirus nucleocapsid protein is phosphorylated and localizes in the cytoplasm by 14-3-3-mediated translocation. J Virol 2005, 79:11476-11486.

24. Boyd KE, Wells J, Gutman J, Bartley SM, Farnham PJ: c-Myc target gene specificity is determined by a post-DNAbinding mechanism. Proc Natl Acad Sci USA 1998, 95:13887-13892.

25. Surjit M, Ganti KP, Mukherji A, Ye T, Hua G, Metzger D, Li M, Chambon P: Widespread negative response elements mediate direct repression by agonist-liganded glucocorticoid receptor. Cell 2011, 145:224-241.

doi:10.1186/1471-2091-13-7

Cite this article as: Surjit et al: The ORF2 glycoprotein of hepatitis E virus inhibits cellular NF-KB activity by blocking ubiquitination mediated proteasomal degradation of IKBa in human hepatoma cells. BMC Biochemistry 2012 13:7.

\section{Submit your next manuscript to BioMed Central and take full advantage of:}

- Convenient online submission

- Thorough peer review

- No space constraints or color figure charges

- Immediate publication on acceptance

- Inclusion in PubMed, CAS, Scopus and Google Scholar

- Research which is freely available for redistribution 